\title{
Mutagenic Effectiveness and Efficiency of Gamma Rays, EMS and NG in Greengram (Vigna radiata L. Wilczek)
}

\author{
Tapas Ranjan Das ${ }^{1 *}$ and Arjun Mohan Prusti ${ }^{2}$ \\ ${ }^{1}$ ICAR- IARI Regional Station, Pusa, Samastipur, Bihar 848125 (India) \\ ${ }^{2}$ Orissa University of Agriculture and Technology, Bhubaneswar, Odisha 751003 (India) \\ *Corresponding author
}

\section{A B S T R A C T}

K e y w o r d s
Greengram, Gamma
rays, EMS, NG,
Mutagenic
effectiveness,
Mutagenic
efficiency
Article Info
Accepted:
18 March 2020
Available Online:
10 April 2020

An experiment was conducted to study the effectiveness and efficiency of one physical mutagen i.e. gamma rays and two chemical mutagens i.e. ethyl methanesulfonate (EMS) and nitrosoguanidine (NG) in greengram. To study the nature and effect of mutagens in greengram, the percentage of lethality, pollen sterility, frequency of chlorophyll mutations, mutagenic effectiveness, mutagenic efficiency and mutation rates of each mutagen were estimated. The values of mutagenic effectiveness indicated that $30 \mathrm{kR}$ in gamma rays, $0.3 \%$ in EMS and $0.005 \%$ in NG treatment are found most effective than other doses/concentrations. NG exhibited as the most effective mutagen whereas gamma rays found as the most efficient mutagen and comparatively higher in mutation rate than EMS and NG. Among all the mutagenic treatments, the maximum efficiency observed in gamma rays 30KR treatment and the lowest efficiency observed in NG $0.015 \%$ treatment based on lethality and pollen sterility. Based on lethality and pollen sterility, the maximum mutation rate among all mutagens was observed in gamma rays treatments followed by EMS.

\section{Introduction}

Greengram [Vigna radiata (L.) Wilczek] is one of the most important pulse crops in India. The conventional approaches of plant breeding have exploited the available genetic variability in greengram, which has in turn led to a narrow genetic base in this crop. Induced mutations provide a powerful means of creating new and useful variability in crop plants both in qualitative and quantitative traits (Das and Misra, 2005). Physical or chemical mutagen induced quantitative variation not only serves as an alternative source of germplasm for natural variation, but it is also useful in generating appropriately linked gene complexes that are responsible for the improvement in yield and other characters of economic interest. Shah et al., (2008) reported that mutagens may cause 
genetic changes in an organism, break the linkages and produce many new promising traits for the improvement of crop plants. Gamma rays, one of the most commonly used physical mutagen in mutation breeding is known to influence plant growth and development by inducing cytological, genetic, biochemical, physiological and morphogenetic changes in cells and tissue (Gunckel and Sparrow, 1961).

Among the chemical mutagens used for induction of both macro- and micro-mutations in various crops, EMS and NG are most effective and frequently used. EMS is reported to be the most effective and powerful mutagen (Minocha and Arnason, 1962) whereas NG reported as the super mutagen (Swaminathan et al., 1968). However, it is observed that only a few mutagenic treatments have been effective in inducing a high frequency of mutation while in others the frequency of induced mutation is low leading to wastage of resources. Thus early knowledge of relative biological effectiveness and efficiency of various mutagens and their selection is essential to recover the high frequency of desirable mutations (Smith, 1972; Das et al., 2006).

The term "mutagenic effectiveness" is a rate of mutations produced by the mutagen concerning its dose whereas the "mutagenic efficiency" is an estimate of mutation rate in relation to the damage (Konzak et al., 1965). An effective mutagen doesn't need to be an efficient one also. Both of these though are two different properties, the use of any mutagen in a plant breeding program depends on both of them.

Hence a study was undertaken to assess the effect of different doses of physical (gammarays) as well as chemical mutagens (EMS and NG) on the frequency of chlorophyll mutation, lethality and pollen sterility to evaluate the relative effectiveness and efficiency of mutagenic treatments and the mutation rate of different mutagens.

\section{Materials and Methods}

Dry and well-filled seeds of a greengram variety, namely Pusa Vishal administered mutagenic treatments with different doses of one physical mutagen i.e. gamma rays and two chemical mutagens i.e. Ethyl Methane sulphonate (EMS) and N-Methyl-NNitrosoguanidine commonly called as Nitrosoguanidine (NG).

Dry seeds were irradiated with gamma rays treatment at Bhaba Atomic Research Centre (BARC), Trombay(India). For treatment with Ethyl Methane sulphonate (EMS) and Nitrosoguanidine (NG), the seeds were presoaked in distilled water for six hours. After pre-soaking, the seeds were blotted dry and treated with freshly prepared chemical mutagen solutions of different concentrations i.e. EMS $(0.15 \%, 0.30 \%, 0.45 \%$ and $0.60 \%)$ and NG $(0.005 \%, 0.010 \%, 0.015 \%$ and $0.020 \%$ ). The seeds were put in the solution for six hours at room temperature $26^{\circ} \mathrm{C}$ with intermittent shaking for providing uniform treatment conditions for all the seeds.

A set of seeds was soaked in distilled water only, which used as control. After the treatment was over, the seeds were thoroughly washed in running tap water for two hours to bleach out the residual chemicals and then dried on blotting paper. The details of mutagenic treatments and the symbols used for treatments are presented in Table 1. To grow the $M_{1}$ generation, the treated seeds were sown in earthen pots (for laboratory study) and in the field in a randomized block design (RBD) with two replication with spacing of $25 \times 10 \mathrm{~cm}^{2}$. A basal dose of $40 \mathrm{~kg}$ $\mathrm{P}_{2} \mathrm{O}_{5} / \mathrm{ha}$ was applied and nitrogen @ $20 \mathrm{~kg} / \mathrm{ha}$ was given as top dressing at 18 days after 
sowing. Observations on survival were recorded in each plot on $30^{\text {th }}$ days after sowing and were calculated as the percent of control from which the lethality (\%) calculated. Mean pollen sterility was determined based on acetocarmine stainability. The selfed seed of all survived plant harvested was used to grow the $\mathrm{M}_{2}$ generation in RBD with three replications with the spacing of $25 \times 10 \mathrm{~cm}^{2}$. The mutagenic treated and control populations were screened daily for different types of chlorophyll mutations such as Albina, Xantha, Chlorine, striata, Viridis from 5th to 12th day after sowing. The frequency of chlorophyll mutants was calculated according to (Gaul, 1960).

The formula proposed by Konzak et al., (1965) was followed for the calculations of mutagenic effectiveness and efficiency by incorporating the mutation frequency values recorded for each mutagenic treatment.

\begin{tabular}{|c|c|}
\hline \multirow[b]{2}{*}{$\begin{array}{l}\text { Mutagenic effectiveness = } \\
\text { (Physical mutagen) }\end{array}$} & Mf \\
\hline & Dose in kR \\
\hline \multirow[b]{2}{*}{$\begin{array}{l}\text { Mutagenic effectiveness = } \\
\text { (Chemical mutagens) }\end{array}$} & Mf \\
\hline & $\mathrm{c} \times \mathrm{t}$ \\
\hline \multirow[b]{2}{*}{ Mutagenic efficiency = } & Mf \\
\hline & $\begin{array}{l}\text { thality }(\mathrm{L}) \\
\text { llen sterility }(\mathrm{P})\end{array}$ \\
\hline
\end{tabular}

Mf = Mutagenic Frequency i.e. frequency of chlorophyll mutations in $\mathrm{M}_{2}$ generation.

$\mathrm{kR}=$ unit of gamma radiation.

$\mathrm{t}=$ duration of treatment with chemical mutagen in hours.

$\mathrm{c}=$ Concentration of chemical mutagens in $\%$

$\mathrm{L}=\%$ Lethality in $\mathrm{M}_{1}$ generation

$\mathrm{P}=\%$ Pollen sterility in $\mathrm{M}_{1}$ generation
Mutation rate (MR) which provides the knowledge of mutations induced by a particular mutagen irrespective of dose or concentration was calculated as follows.

$$
\text { Mutation rate }=\frac{\text { Sum of values of efficiency of particular mutagen }}{-\mathrm{Number} \text { of treatments of a particular mutagen }}
$$

\section{Results and Discussion}

In the present study, the biological damages like lethality and pollen sterility were recorded in $M_{1}$ generation (Table 2). Both parameters were found to increase with increasing doses of mutagens (Fig. 1). In gamma-rays treatments recorded maximum lethality $25.8 \%$ and pollen sterility $8.75 \%$ at $60 \mathrm{kR}$ whereas minimum lethality $2.36 \%$ and pollen sterility $0.58 \%$ at $15 \mathrm{kR}$. In the case of EMS treatments, the maximum lethality $(24.2 \%)$ and pollen sterility $(6.58 \%)$ observed at $0.6 \%$ and a minimum lethality $(1.5 \%)$ and pollen sterility $(0.75 \%)$ at $0.15 \%$. Similar trends were also found in NG i.e. recorded maximum lethality $49.89 \%$ and pollen sterility $9.77 \%$ at $0.02 \%$ dose whereas minimum lethality $(6.53 \%) \&$ pollen sterility $(1.8 \%)$ recorded at $0.005 \%$. The increased lethality and pollen sterility with increasing doses of mutagens also reported by several investigators Das et al., (2006) and Tah (2006) in greengram, Bhosle and Kothekar (2010) in clusterbean. They proved that most of the higher doses of mutagens showed increased pollen sterility and lethality. The probable reason for increased pollen sterility might be meiotic irregularities such as translocations.

Since chlorophyll deficient mutants could not survive long and observed in the treated population for a variable-length period depending on the deficiency of chlorophyll. Therefore, these mutants are of no agronomic value but their frequency in different 
mutagenic treatments of $\mathrm{M}_{2}$ generation was considered to be a standard measure for estimation of effectiveness, efficiency and rate of induced mutation by different mutagens which would ultimately provide the information about the dose for inducing mutations in greengram. In this study, it was observed that an increase in dose or concentration of the mutagen did not increase the relative frequency of chlorophyll mutants; rather a random trend was observed (Table 2).

The frequent of chlorophyll mutation in different treatments of $\mathrm{M}_{2}$ generations varied from $0.27(\mathrm{E} 1)$ to $1.31(\mathrm{~N} 4)$. In general, there was no dose-dependency relationship with chlorophyll mutation. The occurrence of chlorophyll deficient mutant was noticed due to change in gene and a set of genes responsible for chlorophyll mutations (Monika and Seetharaman, 2017). The occurrence of chlorophyll mutations through induced mutagenesis had reported earlier by several researchers in greengram (Vikram et al., 2014), blackgram (Goyal and Khan, 2010), in horse gram (Kulkarni and Mogle, 2013).

The mutagenic effectiveness can be explained the frequency of mutations induced by a unit dose of mutagen while mutagenic efficiency gives an idea of the proportion of mutations in relation to biological damages such as lethality, pollen sterility and chromosomal aberrations. Mutagenic effectiveness at different doses of different mutagens indicated that there is no dose relationship (Table 2). Among the different doses of gamma rays irradiated, the mutagenic effectiveness was maximum at $30 \mathrm{kR}$ followed by $15 \mathrm{kR}$. In EMS, the mutagenic effectiveness was maximum at $0.3 \%$ followed by $0.15 \%$. In the case of $\mathrm{NG}$, the mutagenic effectiveness was maximum (25.33) at $0.005 \%$ followed by $0.01 \%$ (13.83). Hence it could be concluded that NG has higher mutagenic effectiveness compared to all other mutagens and lower doses are more effective among different doses of each mutagen. Similar results previously reported by Rao and Rao (1983); Reddi and Rao (1988); Sharma et al., (2005); Khan et al., (2010) and Girija and Apparao (2011). The greater effectiveness of chemical mutagens over physical mutagen has also been reported by Shah et al., (2008) and Satpute and Fultambkar (2012). Swaminathan et al., (1968) in a study with rice, barley and wheat observed that NG is the more potent mutagen than EMS.

Konzak et al., (1965) showed that mutagenic efficiency provides the best available measure to evaluate different mutagenic treatments. It varies depending upon the criteria selected for its estimation. In the present investigation, mutagenic efficiency based on the lethality in $\mathrm{M}_{1}$ varied from $0.022(\mathrm{~N} 3)$ to $0.222(\mathrm{G} 2)$ and observed that there is no dose-dependent relationship i.e. it did not follow any particular (increasing or decreasing) trend in gamma rays treatments but in case of chemical mutagens, the value of efficiency decreased as there were increases in doses of mutagens i.e. the dose-dependent relationship observed.

Similar results were obtained by Gaikwad and Kothekar (2004) in lentil and Bhosle and Kothekar (2010) in clusterbean. The mutagen efficiency based on pollen sterility demonstrated that there is no dose-dependent relationship for gamma rays and NG whereas, dose-dependent relationship observed for EMS treatments i.e. the value of efficiency decreased as there were increases in doses of EMS (Table 2 and Fig. 2). It was ranged from 0.133 to 1.250 in gamma-rays treatment. In EMS treatments, the range was 0.149 to 0.360 whereas, in NG, the range was 0.078 to 0.422 . Among all the twelve treatments the maximum efficiency based on pollen sterility 
observed in gamma rays $30 \mathrm{kR}$ whereas the lowest efficiency based on pollen sterility observed in NG $0.015 \%$ treatment. Higher efficiency at lower doses of mutagen as observed in the present study might be due to that pollen sterility increased with an increase in doses at a rate faster than the frequency of mutation. Nilan and Konzak (1961) and Konzak et al., (1965) opined that higher efficiency at the lower concentration of a mutagen is due to the fact that biological damage (lethality and sterility) increased within dose at a faster than the mutations.

The mutation rate was calculated by taking the mean values of efficiency for each treatment. This provides an idea of the average rate of mutation induced per mutagen. The mutation rates estimated from the value of mutagen efficiency based on lethality and pollen sterility (Table 3 and Fig. 3 ). Based on lethality the mutation rate varied from 0.053 (NG) to 0.117 (Gamma-rays). Similar trend also observed in case of the mutation rate based on the mutagenic efficiency calculated from pollen sterility value which varied from 0.195 (NG) to 0.535 (Gamma-rays).

A mutagen is useful only if it is effective as well as efficient. Konzak et al., (1965) reported that reduced the rate of injury and the increases the mutation should be compared to the objective in any mutation program. Thus in a mutation breeding program, a high mutation rate accompanied by minimal deleterious effects is desired. But generally, the mutagen that gives the higher mutation rate also induces a high degree of lethality, sterility and other undesirable effects. In the present study, among all the mutagenic treatments, gamma-rays treatments were found to be most efficient.

Table.1 Details of mutagenic treatments

\begin{tabular}{|c|c|c|c|c|}
\hline $\begin{array}{c}\text { Treatment } \\
\text { symbol }\end{array}$ & Mutagens & $\begin{array}{c}\text { Dose/ } \\
\text { concentration }\end{array}$ & $\begin{array}{c}\text { Pre-soaking } \\
\text { period (hours) }\end{array}$ & $\begin{array}{c}\text { Duration of } \\
\text { Mutagenic } \\
\text { treatments (hours) }\end{array}$ \\
\hline G1 & gamma-rays & $15 \mathrm{KR}$ & -- & -- \\
\hline G2 & gamma-rays & $30 \mathrm{KR}$ & -- & -- \\
\hline G3 & gamma-rays & $45 \mathrm{KR}$ & -- & -- \\
\hline G4 & gamma-rays & $60 \mathrm{KR}$ & -- & 6 \\
\hline E1 & EMS & $0.15 \%$ & 6 & 6 \\
\hline E2 & EMS & $0.30 \%$ & 6 & 6 \\
\hline E4 & EMS & $0.45 \%$ & 6 & 6 \\
\hline N1 & EMS & $0.60 \%$ & 6 & 6 \\
\hline N2 & NG & $0.005 \%$ & 6 & 6 \\
\hline N3 & NG & $0.010 \%$ & 6 & 6 \\
\hline N4 & NG & $0.015 \%$ & 6 & 6 \\
\hline C & NG & $0.020 \%$ & 6 & -- \\
\hline
\end{tabular}


Table.2 Effectiveness and efficiency of different mutagenic treatments on greengram

\begin{tabular}{|r|c|c|c|c|c|c|c|}
\hline $\begin{array}{r}\text { Cod } \\
\text { e }\end{array}$ & $\begin{array}{c}\text { Mutagenic } \\
\text { treatment }\end{array}$ & $\begin{array}{c}\% \text { of } \\
\text { lethality } \\
\text { (L) }\end{array}$ & $\begin{array}{c}\text { \% of } \\
\text { Pollen } \\
\text { sterility } \\
\text { (S) }\end{array}$ & $\begin{array}{c}\text { Frequency of } \\
\text { chlorophyll } \\
\text { mutation } \\
\text { (Mf) }\end{array}$ & $\begin{array}{c}\text { Mutagenic } \\
\text { Effectiveness } \\
\text { (ME) }\end{array}$ & $\begin{array}{c}\text { Mutagenic } \\
\text { Efficiency } \\
\text { based on } \\
\text { lethality } \\
\text { (MEFL) }\end{array}$ & $\begin{array}{c}\text { Mutagenic } \\
\text { Efficiency } \\
\text { based on Pollen } \\
\text { sterility } \\
\text { (MEFS) }\end{array}$ \\
\hline G1 & $\gamma$-rays 15kR & 2.36 & 0.58 & 0.36 & 0.024 & 0.153 & 0.621 \\
\hline G2 & $\gamma$-rays 30kR & 4.28 & 0.76 & 0.95 & 0.032 & 0.222 & 1.250 \\
\hline G3 & $\gamma$-rays 45kR & 16.17 & 5.57 & 0.74 & 0.016 & 0.046 & 0.133 \\
\hline G4 & $\gamma$-rays 60kR & 25.80 & 8.75 & 1.18 & 0.020 & 0.046 & 0.135 \\
\hline E1 & EMS 0.15\% & 1.50 & 0.75 & 0.27 & 0.300 & 0.180 & 0.360 \\
\hline E2 & EMS 0.30\% & 6.10 & 2.46 & 0.83 & 0.461 & 0.136 & 0.337 \\
\hline E3 & EMS 0.45\% & 7.82 & 3.31 & 0.69 & 0.256 & 0.088 & 0.208 \\
\hline E4 & EMS 0.60\% & 24.20 & 6.58 & 0.98 & 0.272 & 0.041 & 0.149 \\
\hline N1 & NG 0.005\% & 6.53 & 1.8 & 0.76 & 25.333 & 0.116 & 0.422 \\
\hline N2 & NG 0.010\% & 18.20 & 5.66 & 0.83 & 13.833 & 0.046 & 0.147 \\
\hline N3 & NG 0.015\% & 31.91 & 8.96 & 0.70 & 7.778 & 0.022 & 0.078 \\
\hline N4 & NG 0.020\% & 49.89 & 9.77 & 1.31 & 10.917 & 0.026 & 0.134 \\
\hline
\end{tabular}

Table.3 Mutation rate and correlation between mutagenic effectiveness and efficiency of different mutagens in greengram

\begin{tabular}{|l|c|c|c|c|}
\hline Mutagens & $\begin{array}{c}\text { Mutation rate } \\
\text { based on lethality } \\
\text { (MRL) }\end{array}$ & $\begin{array}{c}\text { Mutation rate } \\
\text { based on pollen sterility } \\
\text { (MRS) }\end{array}$ & \multicolumn{2}{|c|}{ Linear correlation } \\
\hline Gamma-rays & 0.117 & 0.535 & & ME \\
\hline EMS & 0.111 & 0.264 & 0.954 & 0.971 \\
\hline NG & 0.053 & 0.195 & 0.411 & 0.609 \\
\hline
\end{tabular}

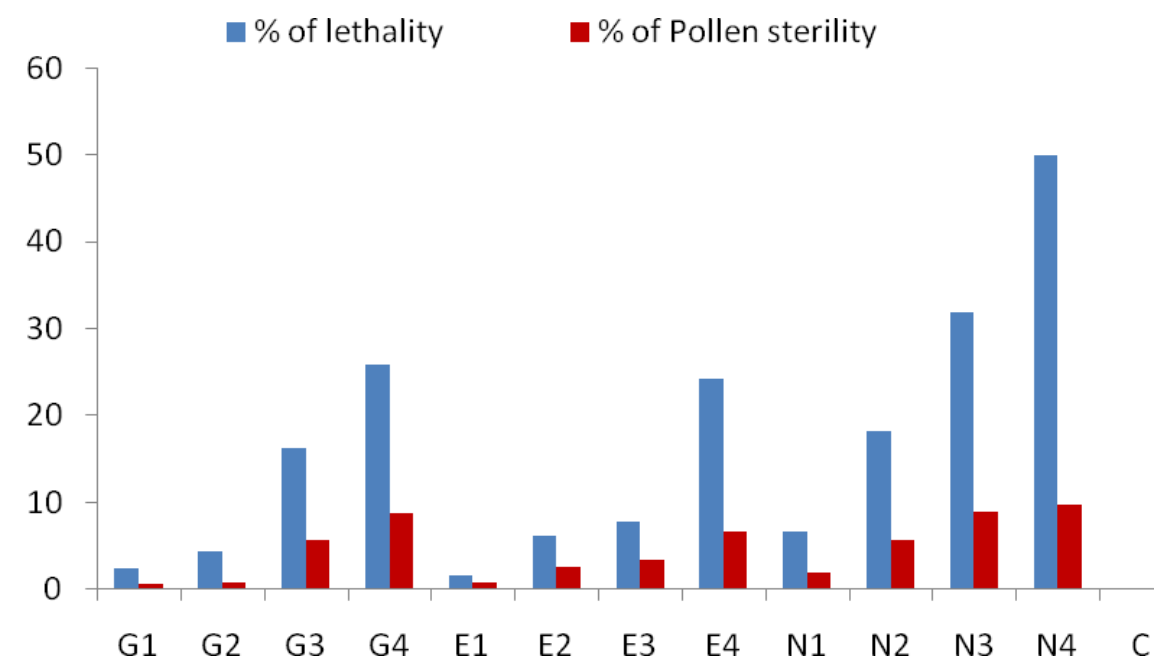

Fig.1 Effect of different mutagenic treatments on lethality and pollen sterility in greengram 


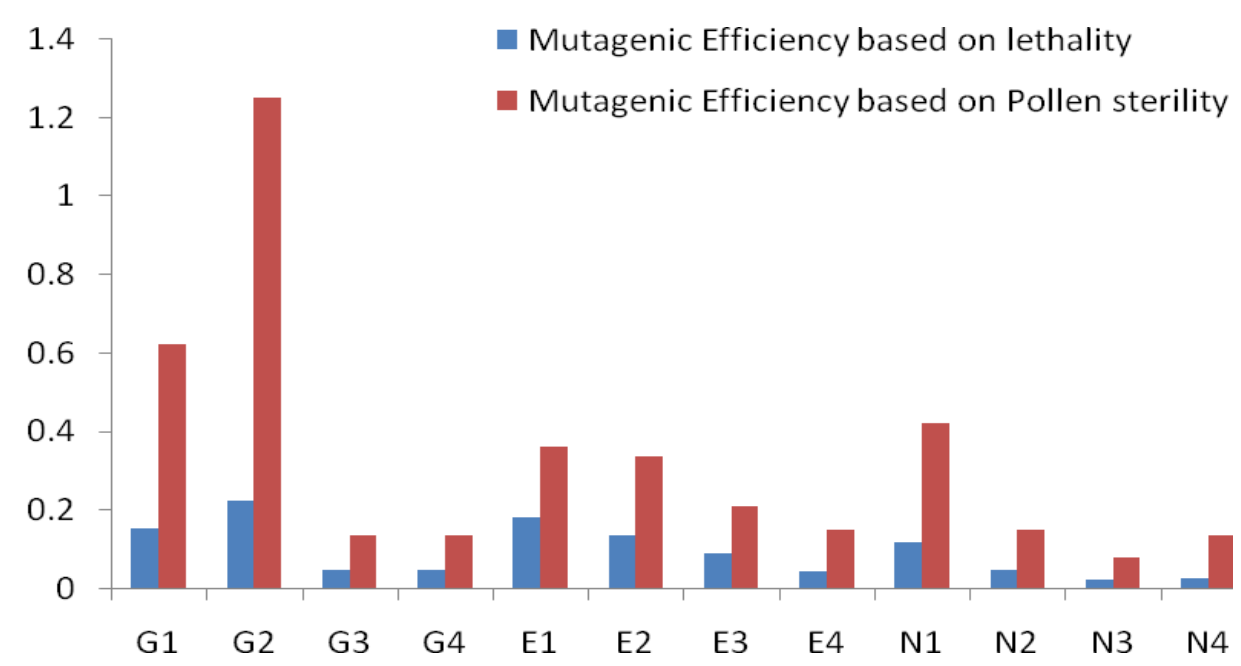

Fig.2 Mutagenic efficiency (\%) of different mutagens in greengram

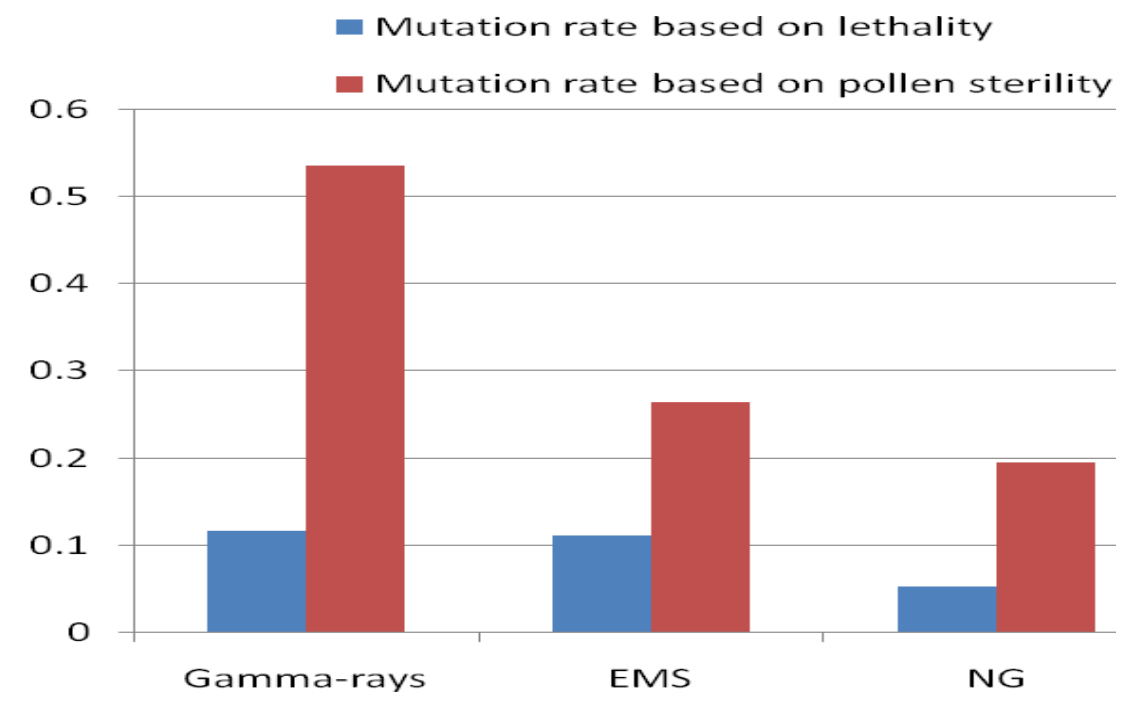

Fig.3 Mutation rates of different mutagens in green gram in terms of mutagenic efficiency for biological effects

The effectiveness and efficiency of mutagen based on leaf chlorophyll, lethality and pollen sterility in greengram are useful in identifying the genetic effect of mutagen. The study also reveals the Gamma rays, EMS and NG have a higher potential to induce significant mutations in greengram.

In this present study, it can be inferred that the lower to moderate doses of the mutagens are more effective than the higher concentrations and among mutagens for creating more useful mutations. The values of mutagenic effectiveness indicated that $30 \mathrm{kR}$ in gamma rays, $0.3 \%$ in EMS and $0.005 \%$ in NG treatment are found most effective than other doses/concentrations. NG has higher mutagenic effectiveness in comparison to EMS and Gamma rays. It was noted that when the mutation rate based on efficiency was considered, the maximum mutation rate (based on lethality and pollen sterility) observed in gamma-rays treatments followed by EMS and NG. 


\section{References}

Bhosale, S.S. and Kothekar, V.S. 2010. Mutagenic efficiency and effectiveness in clusterbean (Cyamopsis tetragonoloba (L.) Taub.). J. Phytol. 2(6): 21-27.

Das, T. R. and Misra, R.C. 2005. Genetic analysis of mutagen induced variability in yield triats in greengrams (Vigna radiata). Environment \& Ecology. 23(2): 381-384.

Das, T. R., Misra, R.C., Sahu, P.K. 2006. Efficiency of mutagenic treatments in expression of macro and micro mutations in $\mathrm{M}_{2}$ generation in greengram and its early predictability on basis of $\mathrm{M}_{1}$ parameters. Environment \& Ecology. 24(2):283-288.

Gaikwad, N.B. and Kothekar, V.S. 2004. Mutagenic effectiveness and efficiency of ethyl methane sulphonate and sodium azide in lentil (Lens culinaris Medik.). Indian J. Genet., 64(1): 7374.

Gaul, H. 1960. Critical analysis of the methods for determining the mutation frequency after seed treated with mutagens. Genet. Agr.12: 297-318.

Girija, S.P. and Apparao, J. 2011. Studies on effectiveness and efficiency of EMS in pigeonpea (Cajanus cajan L.). Bioscience Discovery, 2: 29-31.

Goyal, S. and Khan, S. 2010. Induced mutagenesis in Urdbean (Vigna mungo L. Hepper): a Review, Int. J. Bot. 6(3):194-206.

Gunckel, J.E. and Sparrow, A.H. 1961. Ionizing radiation: Biochemical, Physiological and Morphological aspects of their effects on plants. In: Encycl. Plant Physiol. (ed.) W. Ruhland. XVI: pp. 555-611, Springerverlag, Berlin.

Khan, M., Tyagi, H. and Dutt, S. 2010. Studies on effectiveness and efficiency of gamma rays, EMS and their combination in soybean Glycine max L. Merrill. Journal of Plant Breeding and Crop Science. 2(3):55-58.

Konzak, C.F., Nilan, R.A. Wagner, J. and Foster, R.J. 1965. Efficient chemical mutagenesis. The use of induced mutations in plant breeding (FAO / IAEA Meeting, Rome). Radiat. Bot., (Suppl.) 75: 49-70.

Kulkarni, G.B. and Mogle, U.P. 2013. Effects of mutagen on chlorophyll mutation in horse gram [Macrotyloma uniflorum (Lam) Verdcourt] Bioscience Discovery. 4(2):214-219.

Monika, S. and Seethraman, N. 2017. Induced chlorophyll and viable mutation in Lablab purpureus (L.) sweet Var. typicus through gamma rays and Ethyl Methane Sulphonate. Int J Pharm Bio Sci. 8(2): (B) 240 -249.

Minocha, J.L. and Arnason, T.J. 1962. Mutagenic effectiveness of ethyl methane sulfonate in barley. Nature, 196: 499-499.

Nilan, R. A, and Konzak, C. F. 1961. Increasing the efficiency of mutation induction. In: Mutation and Plant Breeding, NAS-NRC: 437-460.

Rao, G. M, and Rao, V. M. 1983. Mutagenic efficiency, effectiveness and factor of effectiveness of physical and chemical mutagens in rice. Cytologia, 48: 427436.

Reddi, T. V. S and Rao, D. R. M. 1988. Relative effectiveness and efficiency of single and combination treatments using gamma rays and sodium azide in inducing chlorophyll mutations in rice. Cytologia, 53: 491-498.

Satpute, R.A. and Fultambkar, R.V. 2012. Effectiveness and efficiency of the mutagens gamma rays and EMS in soybean (Glycine $\max (\mathrm{L}$.$) Merrill),$ Curr. Bot., 3(2): 18-20.

Shah, T. M., Mirza, J.I., Haq, M.A. and Atta, 
B.M. 2008. Induced genetic variability in chickpea (Cicer arietinum L.). II. Comparative mutagenic effectiveness and efficiency of physical and chemical mutagens. Pak. J. Bot., 40(2): 605613.

Sharma, S. K, Sood, R. and Pandey, D. P. 2005. Studies on mutagen sensitivity, effectiveness and efficiency in urdbean (Vigna mungo (L.) Hepper). Indian J. Genet., 65: 20-22.

Smith, H. H. 1972. Comparative genetic effects of different physical mutagens in higher plants. In: joint FAO/IAEA. Division of Atomic Energy in Food and Agriculture, ed. Induced Mutations and Plant Breeding Improvement IAEA. Vienna, 75-93.
Swaminathan, M.S., E.A. Siddiq., V.N. Savin and. G. Vargughese. 1968. Studies in the treatment of mutation frequencies and identification of mutation in plant Breeding and Phylogenetic significance of some cereals. Mutation in Plant Breeding, 11, IAEA, Vienna. 233-248.

Tah, P. 2006. Induced macromutations in mungbean [Vigna radiata (L.) Wilczek]. International Journal of Botany. 2(3): 219-228.

Vikram, N., Ibrahim, S. M. and Vanniarajan, C. 2014. Frequency and spectrum of chlorophyll mutations in greengram [Vigna radiata (L.) Wilczek] Asian Journal of Bio Science, 9 (2): 204-207.

\section{How to cite this article:}

Tapas Ranjan Das and Arjun Mohan Prusti. 2020. Mutagenic Effectiveness and Efficiency of Gamma Rays, EMS and NG in Greengram (Vigna radiata L. Wilczek). Int.J.Curr.Microbiol.App.Sci. 9(04): 2336-2344. doi: https://doi.org/10.20546/ijcmas.2020.904.280 